\title{
Reaction Engineering for the Industrial Implementation of Biocatalysis
}

\author{
Woodley, John M.
}

Published in:

Topics in Catalysis

Link to article, DOI:

10.1007/s11244-019-01154-5

Publication date:

2019

Document Version

Peer reviewed version

Link back to DTU Orbit

Citation (APA):

Woodley, J. M. (2019). Reaction Engineering for the Industrial Implementation of Biocatalysis. Topics in Catalysis, 62(17-20), 1202-1207. https://doi.org/10.1007/s11244-019-01154-5

\section{General rights}

Copyright and moral rights for the publications made accessible in the public portal are retained by the authors and/or other copyright owners and it is a condition of accessing publications that users recognise and abide by the legal requirements associated with these rights.

- Users may download and print one copy of any publication from the public portal for the purpose of private study or research.

- You may not further distribute the material or use it for any profit-making activity or commercial gain

- You may freely distribute the URL identifying the publication in the public portal

If you believe that this document breaches copyright please contact us providing details, and we will remove access to the work immediately and investigate your claim. 


\title{
Reaction Engineering for the Industrial Implementation of Biocatalysis
}

\author{
John M Woodley* \\ Department of Chemical and Biochemical Engineering \\ Technical University of Denmark (DTU) \\ DK-2800 Kgs. Lyngby \\ Denmark \\ *E-mail: jw@kt.dtu.dk \\ *Tel: +45 45252885 \\ *ORCID: 0000-0002-7976-2483
}

\begin{abstract}
Biocatalytic processes (using enzymes to catalyze synthetic reactions for the production of chemicals) are a potential route to more sustainable manufacturing and today have found application in several industries, but most notably in the pharmaceutical sector. For high-priced pharmaceuticals, the development of new processes is primarily dependent upon biocatalytic development. However, the wider application of biocatalytic processes towards lower-priced chemicals will demand reaction engineering to be considered, alongside biocatalyst development. Bioreaction engineering includes an evaluation of the thermodynamics and reaction kinetics, as well as the stability of the biocatalyst. In this brief article, tools to assist in the collection and evaluation of reaction engineering data will be discussed, and illustrated using biological oxidation as an example.
\end{abstract}

Keywords: Biocatalytic processes, bioreaction engineering, enzyme kinetics, biocatalyst stability. 


\section{Introduction}

As the drive towards ever more sustainable chemical production methods continues, the use of enzymes to catalyze synthetic reactions (biocatalysis) is increasingly being seen as one potential solution. Whilst, high selectivity is the primary characteristic of enzymatic reactions, such reactions also usually take place under relatively benign conditions (e.g. neutral $\mathrm{pH}$, ambient temperature and pressure). These two features alone make enzymes of great interest to synthetic chemists, as a complement to conventional catalytic methods, where more extreme conditions frequently lead to by-products and impurity formation [1]. In the pharmaceutical industry stereo- and regio-selectivity is often essential to create optically-pure chiral molecules, and avoid multiple protection and de-protection of molecules, respectively. Frequently the implementation of an enzymatic reaction can therefore circumvent several conventional catalytic steps. Nevertheless, and perhaps of even greater significance, is the very special ability to design enzymes with desirable properties based on protein engineering technologies. This is a field that has grown enormously since its initial development in the 1980s [2]. Today, this opens the possibility of using new reactants in established reactions, or even catalyzing entirely new reactions, never found previously in Nature [3]. These highly desirable features of enzymes mean that over the last 30 years several hundred enzyme-based processes have been implemented in industry, in particular in the production of small-molecule pharmaceuticals [4]. The next development will be to apply enzyme-based catalysis to medium-priced products, where there have been a more limited number of success stories to date. As enzyme production at large-scale becomes ever more effective, the cost of enzyme catalysts decreases, and this together with a much wider range of commercially available enzymes means that enzyme-based catalysis will find an increasing number of new applications.

All these developments paint an optimistic picture of the possibility of using biocatalysis to help solve the sustainability challenges of the chemical industry and a growing opportunity for the development of new enzyme-based reactions. However, two major challenges need to be addressed in the coming period. First, for higher-priced products, such as pharmaceuticals, the speed and efficiency of biocatalyst development needs to be accelerated to match the very aggressive time line for the creation of new pharmaceutical molecules and their manufacturing processes [5]. Secondly, for medium-priced products a number of reaction engineering methods need to be established [6], since more emphasis will be placed on process economics, rather than development speed alone.

In this paper the second of these challenges will be addressed and illustrated with the application of oxidases for industrial production of medium-priced chemical products.

\section{Application of biological catalysis}

The current motivation to improve industrial chemical processes is driven by a desire to implement sustainable production methods. Hence, clean and sustainable reagents are required, with processes based on renewable (sustainable) feedstocks, renewable (sustainable) catalysts, using good atom efficiency and producing low amounts of waste. These chemistry-driven requirements for the future are reflected also in the need for process improvements, including the use of highly selective operations, intensified operations, use and recycle of all process streams, few process steps and few $\mathrm{pH}$ changes, temperature changes and solvent changes through a given process. Although biocatalysis helps fulfil many of these chemical and process requirements for the future, replacement of existing routes remains challenging, since frequently 
the cost of plant is already written off, leaving little economic incentive to change the process. Nevertheless, where the opportunity exists for capacity increases, opportunities to implement new technology can be exploited. Indeed predictions indicate significant increases in the demand for mediumpriced chemicals in the future, whilst alongside this, waste should be minimized and environmental emissions controlled [1]. Hence new opportunities will be forthcoming for biocatalysis in the manufacture of chemicals, with an increased emphasis on economics. Indeed, for medium-priced chemicals, economics will play a much bigger role in process implementation than for the development of pharmaceutical production processes. Hence the reaction yield (g product/g reactant), space-time yield (g product/L reactor volume.hour) and product concentration (g product/L reaction liquid volume) will be of paramount importance, alongside effective use of the biocatalyst (g product/g biocatalyst). These four performance metrics will drive the necessary reaction engineering evaluation of the new processes.

Biological catalysts are of three basic types, as illustrated in Figure 1.

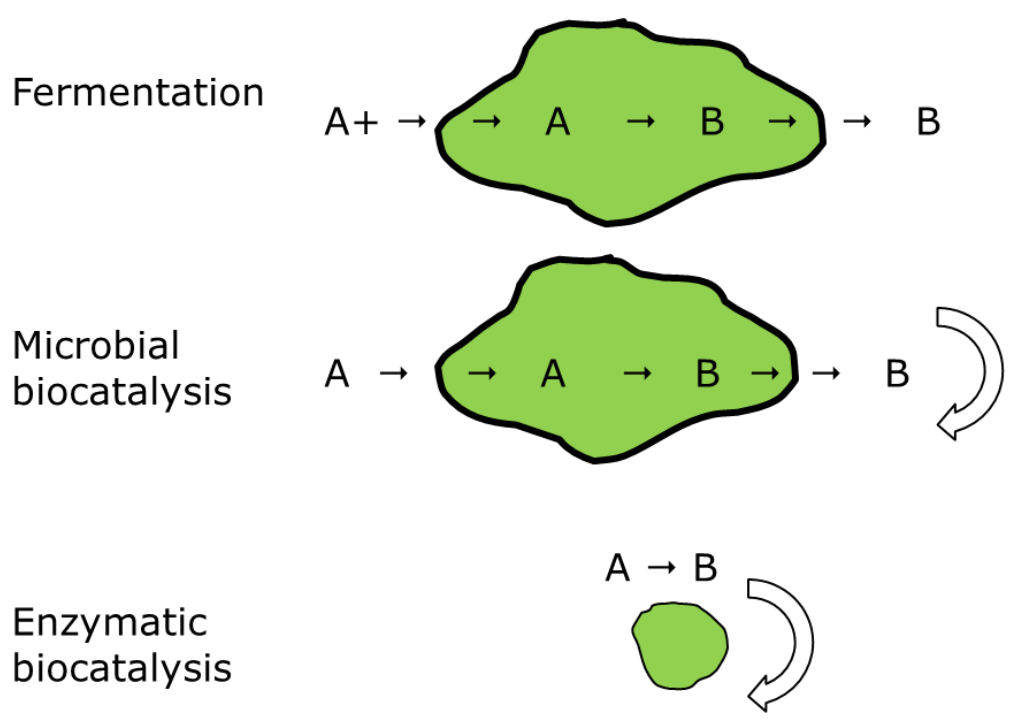

Figure 1: Types of biological catalysts. A represents the reactant, and B, product.

The first type of biological catalysis is based on growing cells, where product formation through enzyme action is associated with cell growth. This means that the biocatalyst is produced simultaneously with the reaction(s) being carried out. There are several challenges associated with this for chemical production. For example, as an autocatalytic reaction this requires the diversion of a significant amount of reactant to help grow the cells (thereby lowering the reaction yield (yield of product on reactant)), and at a reaction rate which is dependent on the cell growth rate (thereby limiting productivity). In addition to these problems, the selectivity often associated with the use of a single enzyme may be compromised by multiple reaction pathways in the cell, resulting in by-products. This also lowers the reaction yield and causes problems downstream for product recovery and purification. Finally, the concentration of product that can be achieved in the fermenter is limited by the tolerance of a given cell to high product concentrations. Many compounds (especially non-natural ones) prove inhibitory or toxic to cells at concentrations far beneath 
those necessary for effective product recovery. Although some specific chemical products suit fermentation well as the means of their production, development times are long and in many cases a true catalytic system may prove more attractive.

This brings us to the second type of system, which is a catalytic version of the first scheme. Here cell growth and product formation have been separated. In principle, provided the cells are stable enough to allow recycle, the yield of product on reactant can be high enough to justify lower-priced product synthesis. Likewise the reaction rate can be altered simply by adding more biocatalyst, and provided this is proportional to product formation, the cost of cell production will not dominate the costs.

In the final approach this can be simplified still further by pretreatment of the cells prior to the reaction, in order to allow permeabilization or cell disruption, such that reactions can be carried out independent of any cellular constraints (such as the need to balance redox and energy). Operating as a cell-free extract (commonly termed CFE) therefore comes with a number of advantages, and allows extra degrees of freedom (see Table 1). Likewise such systems can easily be integrated with other enzymatic or chemical catalytic steps as part of a longer synthesis route.

Table 1: Characteristics of alternative strategies for the application of biological conversion to chemical synthesis. (WC represents whole-cell and CFE, cell-free extract).

\begin{tabular}{|l|l|l|l|}
\hline $\begin{array}{l}\text { Bioconversion } \\
\text { strategy }\end{array}$ & $\begin{array}{l}\text { Biocatalyst } \\
\text { format }\end{array}$ & Limitations & $\begin{array}{l}\text { Design } \\
\text { variables }\end{array}$ \\
\hline Fermentation & WC & $\begin{array}{l}\text { - Yield limited by cell growth } \\
\text { Rate limited by cell growth } \\
\text { rate } \\
\text { Need to balance redox and } \\
\text { energy in cell }\end{array}$ & - \\
\hline $\begin{array}{l}\text { Microbial } \\
\text { biocatalysis }\end{array}$ & WC & $\begin{array}{l}\text { Need to balance redox and } \\
\text { energy in cell }\end{array}$ & $\begin{array}{l}\bullet \text { Biocatalyst recycle } \\
\text { Biocatalyst concentration in the } \\
\text { conversion stage }\end{array}$ \\
\hline $\begin{array}{l}\text { Enzymatic } \\
\text { biocatalysis }\end{array}$ & CFE & $-\quad \begin{array}{l}\text { Biocatalyst recycle } \\
\text { Biocatalyst concentration } \\
\text { Independent redox regeneration }\end{array}$ \\
\hline
\end{tabular}

\section{Reaction engineering}

The required reaction engineering to implement a biocatalytic process from a known enzyme catalyzed reaction revolves around three basic requirements. First the biocatalytic reaction needs to be effective from the perspective of the potential economic return that can be made in the process. This necessary requirement is calculated not only by an adequate price difference between the product and reactant, but also by the yield of product on reactant. In some cases the reaction yield may itself be limited by the thermodynamics of the reaction and therefore initial investigations into thermodynamics are of 
considerable importance. For many years the majority of enzyme-based reactions were carried out in aqueous media alone, driving hydrolytic reactions in a favorable direction. Nevertheless while natural metabolic pathways in microbial cells allow for poor thermodynamics of one reaction, by coupling it with a more thermodynamically favorable reaction, single enzyme steps run in biocatalytic processes sometimes need to be run in the unfavorable direction (e.g. to create a chiral center). In such cases coupling can also be used [7], or other techniques employed such as using an excess of reactant, or removing the product as the reaction runs (so-called in situ product removal (ISPR)[8]). In principle once the thermodynamics are establish, mathematical models can be used to predict changes in the yield achievable under different reaction conditions.

The second requirement is that reactions are fast enough. It is a widely held assumption that enzymes are very fast catalysts. This holds true when enzymes are used to convert their natural reactants, although evolution always optimizes enzymes for given requirements in a wider biological context [9]. However, whenever enzymes are taken outside their natural environment (which itself will vary from enzyme to enzyme), their efficiency will fall. Likewise those products (and intermediates) of greatest interest to the chemical industry will demand the application of enzymes converting non-natural reactants, frequently never before seen in Nature. In such cases it is clear that the fit of the reactant into the active site will be poor, resulting in a low rate of reaction. Fortunately protein engineering technologies (where amino-acids in the active site are swapped to alter the characteristics of that site) have been found very suitable to improve the rates of such unusual reactions. Measuring the reaction rate will also give information about the concentration of biocatalyst required to achieve a given productivity and thereby the size of reactors to be employed. In all cases this also enables an evaluation of potential mass transfer limitations. This can be either intra-phase mass transfer, where reactant needs to be transported to the active site through a support material, or else inter-phase mass transfer, where reactant is transferred to the aqueous reaction phase (containing enzyme) from a gas, water-immiscible liquid or solid phase. Such situations are surprisingly common and make for particularly interesting reaction engineering problems. As with thermodynamics, when the kinetics can be described by a rate law, then predictions can be made about the rate under different reaction conditions.

Finally, the third requirement is that the enzymes used to catalyze the reactions are stable under reaction conditions, for sufficient time. It is not only challenging to measure their stability, but even harder to develop mathematical models good enough to predict the stability under other conditions. One of the major challenges is therefore to evaluate and develop models to describe not only the thermal stability (the so-called thermodynamic stability) of enzymes, but also kinetic stability as observed under industrial reaction conditions. By definition, those catalysts with the highest stability in an industrial environment are almost impossible to measure in a meaningful way in the laboratory. This makes 'scale-down' measurements very difficult to carry out, especially since translation between conditions is so difficult. The Bommarius group (at GeorgiaTech, Atlanta, USA) have made significant progress through high temperature stability tests, but this remains a complex area for reaction engineering [10,11].

Unlike the reaction engineering of chemo-catalytic processes, where frequently the aim is to find the conditions under which a given catalyst works best (in particular temperature and $\mathrm{pH}$ conditions), one of the characteristics of reaction engineering of biocatalytic processes is that much of the work is focused on establishing the conditions which suit the process best (in particular reactant and biocatalyst 
concentrations). Here the biocatalyst can be altered (though protein engineering) giving an extra degree of freedom. The aim is to find common conditions which satisfy not only thermodynamic constraints, but also kinetics and stability requirements. Finding the optimal conditions remains a big experimental puzzle, since not all phenomena can yet be modelled. Despite great progress there remain several challenges. In order to illustrate these challenges, the application of some of these principles to the development of oxidase-based technology will be outlined in the following sections.

\section{Use of oxidases}

Oxidation is one of the most important reactions in organic chemistry and is an integral part of many industrial syntheses. Biological oxidation is particularly attractive because it allows the use of molecular oxygen as the oxidant under benign conditions [12-15]. Hence reactions using the enzyme classes of oxidases and oxygenases are both of great interest. In particular reactions can be carried out with these enzymes selectively, meaning the precise positioning of a hydroxyl group for example, as well as the creation of chiral centers. The enormously interesting chemistry however also requires careful reaction engineering. Hence, despite some clear successes only a few reactions have been scaled-up $[16,17]$. This is in part since due to three major challenges with this type of reaction, which will be addressed in the following.

\subsection{Oxygen transfer and supply}

The enzymes which catalyze oxidations usually work in an aqueous environment, so the second reactant (oxygen) must be dissolved in the water phase to allow the reaction to take place. Since oxygen is only sparingly soluble in water (around $0.265 \mathrm{mM}$ at $30^{\circ} \mathrm{C}$ ), this presents a number of problems. It is interesting that such problems rarely occur in the chemical equivalent reactions since the oxidant is rarely molecular oxygen and the reaction medium rarely water. Indeed the solubility of oxygen in other solvents is significantly higher [18].

First it should be recognized that the maximum solubility is a function of the gas phase partial pressure with which it is in contact. Hence using pure oxygen, rather than air affords a five-fold increase in maxiumum solubility. Likewise increases in partial pressure can result from the use of pressurized gas.

The oxygen transfer rate can be described by the well-known model shown in Equation 1.

$\begin{array}{ll}\mathrm{OTR}=\mathrm{K}_{\mathrm{L}}\left(\mathrm{C}_{\mathrm{O}}^{*}-\mathrm{C}_{\mathrm{O}}\right) & \text { Equation } 1\end{array}$

where OTR is the oxygen transfer rate, $\mathrm{K}_{\mathrm{L}} \mathrm{a}$, the mass transfer coefficient and $\mathrm{C}_{0}{ }^{*}$ and $\mathrm{C}_{\mathrm{O}}$ the oxygen concentrations in the aqueous phase in equilibrium with the gas phase and dissolved in the bulk of the aqueous solution, respectively.

Assuming an ideal case where $C_{0}$ can be neglected, then the maximum possible oxygen transfer rate can be calculated as follows:

$\mathrm{OTR}_{\max }=\mathrm{K}_{\mathrm{L}} \mathrm{a}\left(\mathrm{C}_{\mathrm{O}}{ }^{*}\right)$

Equation 2

One can assume different values of $K_{\mathrm{L}}$, which might vary from $500 \mathrm{~h}^{-1}$ at a large-scale, to $50 \mathrm{~h}^{-1}$ in the laboratory. In this way a best case scenario can be calculated, illustrated in Figure 2. 


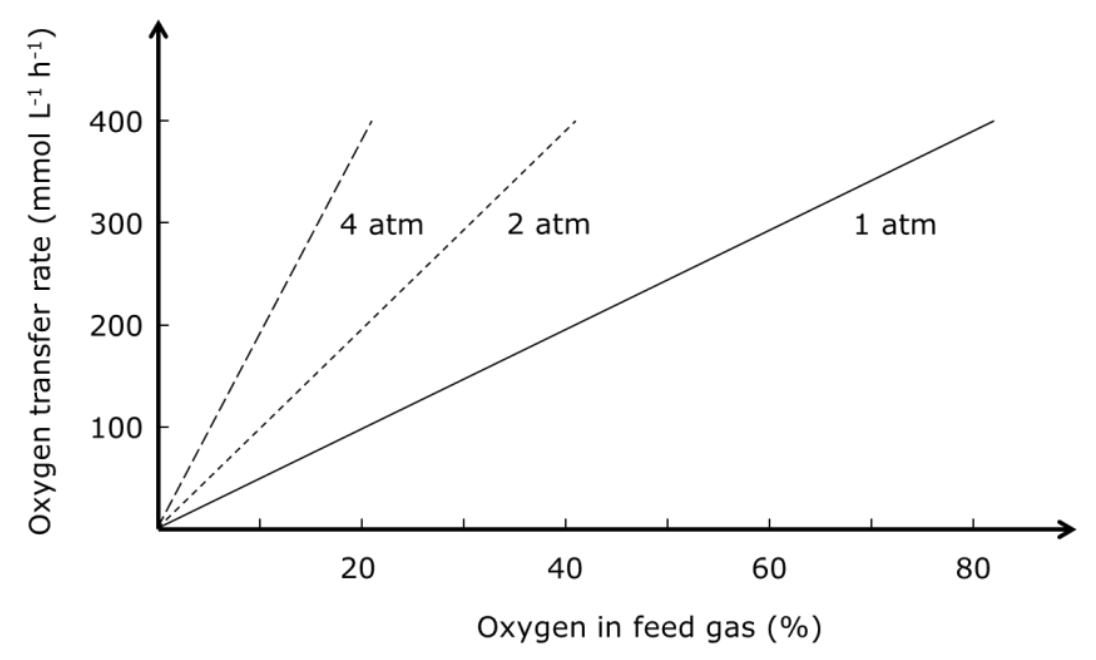

Figure 2. Oxygen transfer rates at $30^{\circ} \mathrm{C}$ as a function of oxygen concentration in the feed gas and pressure. Assumed $\mathrm{K}_{\mathrm{L}} \mathrm{a}$ of $500 \mathrm{~h}^{-1}$.

Using such data gives the maximum amount of oxygen that can be transferred, and this can then be used to calculate the rate of oxygen supply to the reaction, dependent upon the stoichiometric requirements. Cofactor uncoupling (a feature of many oxygenases) consumes oxygen, as well as the cell-growth in cases where biocatalysts are used as growing cells. This again emphasizes a further advantage of using a cell-free extract. Interestingly the stoichiometric oxygen requirement of oxidases is half that of oxygenases, which also affects the maximum reaction rate that can be achieved, based on the maximum oxygen transfer rate. The result of these calculations is that, dependent upon the reaction type and biocatalyst format, oxidation rates are relatively low, unless air is enriched with oxygen or the gas-phase is pressurized. Likewise the small amount of dissolved oxygen possible in the aqueous reaction phase means that continuous supply is essential. These conclusions are clearly important for industrial operation, but they may also have implications for laboratory scale screening of new biocatalysts.

Industrial operation is probably still best in stirred tanks (using enriched air and/or higher pressures if required). In some cases the enzymes may be sensitive to the gas-liquid interface, meaning operation in membrane reactors may be more suitable. In recent years alternative reactors such as the agitated cell reactor have also become available for testing high reaction rates at high $K_{\llcorner}$a values [19]. Since $K_{\llcorner}$a generally increases with scale it is also important to consider how to carry out laboratory (scaled-down reactions) in such a way as to mimic larger scale operation.

\subsection{Enzyme efficiency}

The limited oxygen solubility in water not only limits the maximum possible oxygen supply rate, but also has a direct effect of the efficiency with which a given oxidation enzyme is used. This is because the maximum solubility of oxygen is so low that potentially the enzyme will not be fully saturated with this reactant at that concentration. The extent of this problem is best understood by inspection of the rate law. 
For a two-substrate reaction such as an oxidase the reaction is best described by the ping-pong bi-bi reaction mechanism. The corresponding version of the rate law is given in Equation 3.

$\mathrm{V}=\mathrm{V}_{\max } \mathrm{C}_{\mathrm{S}} \mathrm{C}_{\mathrm{O}} /\left(\mathrm{C}_{\mathrm{S}} \mathrm{C}_{\mathrm{O}}+\mathrm{C}_{\mathrm{S}} \mathrm{K}_{\mathrm{MO}}+\mathrm{C}_{\mathrm{O}} \mathrm{K}_{\mathrm{MS}}\right)$

Equation 3

where $V$ is the rate of reaction, $V_{\max }$, the maximum rate of reaction (proportional to the enzyme concentration), $C_{S}$ is the concentration of substrate, $C_{0}$ the concentration of oxygen, $K_{M o}$ the Michaelis constant for oxygen and $\mathrm{K}_{\mathrm{MS}}$ the Michaelis constant for the reactant.

If the enzyme is fully saturated with reactant (S) (i.e. $C_{S}>K_{M S}$ ), then the equation can be rewritten as:

$\begin{array}{ll}\mathrm{V} / \mathrm{V}_{\max }=\mathrm{C}_{\mathrm{O}} /\left(\mathrm{C}_{\mathrm{O}}+\mathrm{K}_{\mathrm{MO}}\right) & \text { Equation } 4\end{array}$

It is clear therefore that unless the $C_{0}$ is significantly greater than $K_{M O}$, the efficiency with which the enzyme is used $\left(\mathrm{V} / \mathrm{V}_{\max }\right)$ will be a fraction of unity. It is not unreasonable to assume many oxidases would have a low $\mathrm{K}_{\mathrm{MO}}$, since oxygen is the natural second reactant of the enzyme. Nevertheless evolutionary pressures to reduce $\mathrm{K}_{\mathrm{MO}}$ appear to be limited [9], and indeed metabolic control is afforded by operating enzymes around their $\mathrm{K}_{\mathrm{M}}$ value. The interesting conclusion is that $\mathrm{K}_{\mathrm{MO}}$ can frequently be around the same value as that of $\mathrm{C}_{0}$, and may even be higher in some cases.

The implications for reaction engineering are that many reactions at larger-scale need to be supplied with high partial pressure oxygen, or alternatively attempts made to lower the $\mathrm{K}_{\mathrm{MO}}$ by protein engineering, in order to use the enzyme effectively. Biotechnologists and chemists, interested in discovering new oxidase activities, regularly screen the enzymes under atmospheric conditions, without any particular attention to oxygen supply. This is of course an efficient and quick method of assay. However this may also miss cases where the $\mathrm{K}_{\mathrm{MO}}$ is relatively high, ultimately giving inefficient enzyme use when translated to reactor operation.

\subsection{Determination of $\mathrm{K}_{\mathrm{MO}}$}

The importance of the $\mathrm{K}_{\mathrm{MO}}$ value, as indicated in the preceding text, led us to consider the best way to determine the $\mathrm{K}_{\mathrm{MO}}$ value of a given enzyme.

The simplest method is probably based on batch experiments, whereby initial reaction rates are measured at varying substrate concentrations using a continuous supply of air bubbles, as well as enriched air to varying extents to give a full picture of the kinetic data. It is important, in order to minimize errors, that a substantial range of conditions are used, in particular at oxygen concentration well above the likely $\mathrm{K}_{\mathrm{MO}}$, such that extrapolation to obtain the accurate constants is done correctly. In such experiments it is important that the dissolved oxygen concentration is measured and used to determine the parameters in the kinetic rate law. The supply concentration in this regard is not relevant. Likewise the scale must be small enough that the concentration of both the gas phase and the liquid is the same throughout that phase, meaning both are 'ideally well-mixed'. A reactor of around $200 \mathrm{~mL}-1 \mathrm{~L}$, with adequate agitation will usually fulfil this.

A second method which we have recently pioneered involves a modification of the established tube-in-tube reactor technology. Here gas phase, at various partial pressures of oxygen can be supplied via an outer tube, and allowed to cross a gas-permeable membrane to an inner tube, containing enzyme and substrate 
solution. The reactor has been developed to operate with ramp kinetics (in the dispersed-flow mode). These features of the reactor taken together mean that:

1. The material flows through the reactor in plug flow

2. The residence time of material in the reactor accurately reflects the reaction time

3. Adjusting the flowrate can therefore be used to adjust the reaction time

4. The concentration of oxygen to which enzyme is exposed is constant throughout the reaction, and can be directly determined by the oxygen partial pressure in the outer tube

The reactor has been fully automated such that a complete kinetic characterization can be undertaken in a matter of hours. A description of the apparatus as well as illustrative data can be found in the publication of Ringborg and co-workers [20].

\subsection{Catalase}

In all cases where oxidases are used it has become clear that the by-product hydrogen peroxide usually produced can limit the reaction. In the case of alcohol oxidation to aldehydes for example the hydrogen peroxide may itself react with the aldehyde. Nevertheless hydrogen peroxide is well known to reduce enzymatic activity, meaning that catalase (a relatively cheap, active and stable enzyme), must be added to ensure that the hydrogen peroxide is immediately degraded to water and oxygen as it is formed. Interestingly this reaction results in the formation of a half a mole of oxygen from each mole of hydrogen peroxide formed, which is fed-back to the reaction. Hence the overall stoichiometry is improved.

\section{Concluding remarks}

The oxidase example used in this text illustrates well the challenges of scale-up and process implementation in biocatalysis. In this case it would appear, from the kinetic analysis, that it can be beneficial to screen for low $\mathrm{K}_{\mathrm{MO}}$ mutants as well as other beneficial traits of a given enzyme. Such an approach implies the current methods of process design based on building a process around given catalyst properties needs to the altered for biocatalysis. Indeed the introduction of an extra degree of freedom to allow protein modification is not only beneficial for chemistry but also process engineering. In order to fully exploit this property of enzymes it is important to reverse the design paradigm such that enzymes are designed to fit the process, rather than the other way round, or even using both enzyme and process engineering to design optimal processes [21]. Such a paradigm places particular importance on collecting kinetic data and subsequent modelling using rate laws. Development of such kinetic evaluation will ultimately allow the full exploitation of protein engineering.

In reality a comprehensive reaction engineering analysis requires a study of not only reaction kinetics and thermodynamics but also enzyme stability. In the case of oxidases the kinetics are perhaps first and foremost dominant, but it is clear enzyme stability must also be considered, not least because oxygen may react with cysteine residues on the catalytic protein surface, thereby decreasing activity. Indeed there are several reaction engineering challenges which make this area of biocatalysis particularly interesting to study in more detail. In doing so it is hoped that many more reactions will be assessed in sufficient depth that they become suitable for scale-up, capitalizing on all the advantages of using enzymes from the perspective of sustainability. 


\section{References}

1. Sheldon RA, Woodley JM (2018) The role of biocatalysis in sustainable chemistry. Chem Rev 118:801834

2. Arnold F (2018) Directed evolution: Bringing new chemistry to life. Angew Chem Int Ed 57:4143.4148

3. Kan SB, Lewis RD, Chen K, Arnold FH (2016) Directed evolution of cytochrome c for carbon-silicon bond formation: Bringing silicon to life. Science 354:1048-1051

4. Pollard DJ and Woodley JM (2007) Biocatalysis for pharmaceutical intermediates: the future is now. Trends Biotechnol 25:66-73

5. Truppo MD (2017) Biocatalysis in the pharmaceutical industry: The need for speed. ACS Med Chem Lett 8:476-480

6. Ringborg RH, Woodley JM (2016) The application of reaction engineering to biocatalysis. Reaction Chem Engng 1:10-22

7. Abu R, Woodley JM (2015) Application of enzyme coupling reactions to shift thermodynamically-limited biocatalytic reactions. ChemCatChem 7:3094-3105

8. Woodley JM, Bisschops M, Straathof AJJ and Ottens M (2008) Future directions for in-situ product removal (ISPR). J Chem Tech Biotechnol 83:121-123

9. Bar-Even A, Noor E, Savir Y, Liebermeister W, Davidi D, Tawfik DS, Milo R (2011) The moderately efficient enzyme: Evolutionary and physicochemical trends shaping enzyme parameters. Biochem 50:4402-4410

10. Polizzi KM, Bommarius AS, Broering JM, Chaparro-Riggers JF (2007) Stability of biocatalysts. Curr Opin Chem Biol 11:220-225

11. Bommarius AS, Paye MF (2013) Stabilizing biocatalysts. Chem Soc Rev 42:6534-6565

12. Fu X (2005) Applications of oxidoreductases:Recent progress. Ind Biotechnol 1:38-50

13. Turner NJ (2011) Enantioslecetive oxidation of C-O and C-N bonds using oxidases. Chem Rev 111:40734087

14. Liu J, Wu S, Li Z (2018) Recent advances in enzymatic oxidation of alcohols. Curr Opin Chem Biol 43:7786

15. Dong J, Fernández-Fueyo E, Hollmann F, Paul C, Pasic M, Schmidt S, Wang Y, Younes S, Zhang W (2018) Biocatalytic oxidation reactions - a chemist's perspective. Angew Chem Int Ed 57:9238-9261

16. Brummund J, Sonke T, Müller M (2015) Process development for biocatalytic oxidations applying alcohol dehydrogenases. Org Proc Res Dev 19:1590-1595

17. Tan Q, Qiu J, Luo X, Zhang Y, Liu Y, Chen Y, Yuan J, Liao W (2018) Progress in one-pot bioconversion of cephalosporin $C$ to 7-aminocephalosporanic acid. Curr Pharma Biotechnol 19:30-42

18. Sato T, Hamad Y, Sumikawa M, Araki S and Yamamoto H (2014) Solubility of oxygen in organic solvents and calculation of the Hansen solubility parameters of oxygen. Ind Eng Chem Res 53:19331-19337

19. Toftgaard Pedersen A, Carvalho T, Sutherland E, Rehn G, Ashe R, Woodley JM (2017) Biocatalytic oxidation in a continuous agitated cell reactor. Biotech Bioeng 114: 1222-1230

20. Ringborg RH, Toftgaard Pedersen A, Woodley JM (2017) Automated determination of oxygen dependent enzyme kinetics in a tube-in-tube microreactor. ChemCatChem 9:3285-3288

21. Woodley JM (2017) Integrating Protein Engineering with Process Design for Biocatalysis. Phil Trans $R$ Soc A 376:20170062 